\title{
Edição Especial
}

No editorial da edição passada, evocamos a comunidade ortodôntica a questionar as "verdades" correntes. A busca incessante das causas e conseqüências envolvidas na nossa profissão nos permite, com a colaboração de novas descobertas, abordar os problemas de maneira mais apropriada. O conhecimento baseado em evidências cientificamente comprovadas nos autoriza a encarar alguns fatos com mais segurança. Historicamente, a reabsorção radicular ortodonticamente induzida é um desses fatos que assombra os clínicos e que motiva inúmeras pesquisas cujo único objetivo vem sendo elucidar seu mecanismo e fatores envolvidos. Graças aos diversos trabalhos já publicados, muitos mitos foram esclarecidos e abandonados, mas a suscetibilidade de um paciente ter reabsorções dentárias durante o tratamento ortodôntico e, a possibilidade deste fenômeno ter uma natureza hereditária, ainda inquietam a comunidade ortodôntica.

Procurando esclarecer o papel da hereditariedade nas reabsorções radiculares decorrentes da movimentação ortodôntica, essa edição traz à tona uma série de artigos sobre o assunto. Concordamos que a especificidade técnica e a terminologia própria assustam e dificultam a compreensão de resultados por parte de profissionais clínicos de qualquer especialidade médica e odontológica. Diante da relevância do tema, e conscientes de que precisamos divulgar somente fatos baseados em evidências, convidamos o Prof. Dr. Alberto Consolaro, reconhecidamente uma autoridade sobre o assunto, e equipe a apresentarem suas análises críticas de quatro artigos, publicados em revistas internacionais, sobre a hereditariedade e a reabsorção radicular ortodôntica. Ao material foram acrescentadas uma importante entrevista com um geneticista renomado internacionalmente (Dr. Antônio Richieri-Costa, do Centrinho de Bauru), um tópico especial e um guia que fala sobre os critérios para análise crítica de artigos científicos relacionados com movimentação dentária induzida e reabsorções dentárias. Todo esse material oferecerá ao leitor um verdadeiro compêndio do "status quo" da heredita- riedade/genética versus reabsorção radicular.

Reafirmando como a corrente de estudos sobre o tema é atual, foi incluído, entre os artigos inéditos, um trabalho dos autores Odebrecht, Canto e Bortolon que aborda a influência do bruxismo na reabsorção radicular. Na clássica seção "Entrevista", o Prof. Dr. Douglas Sinn (da Universidade do Texas, EUA) responde interessantes questões sobre abordagens de cirúrgica ortognática e de ATM, além de falar sobre sua trajetória acadêmica. A edição apresenta outros artigos inéditos como o questionamento apresentado por Pinzan, Pinzan, Freitas, Henriques e Almeida sobre os históricos critérios da Análise de Steiner. Também é interessante o artigo exposto por Ilha Filho, Fava, Aquotti, Reis, Bonni e Mena sobre as alterações degenerativas da ATM em pacientes com disfunção craniomadibular. Finalmente, não poderíamos deixar de chamar a atenção do leitor sobre dois artigos que discorrem a respeito da Classe II, descrevendo os efeitos do clássico tratamento com o AEB, e de duas modalidades muito usadas atualmente, o avanço mandibular fixo (exemplificado pelo Jasper Jump) e o uso de distalizadores intra-bucais (exemplificado pelo Distal Jet), artigos de autoria de Oliveira Jr. \& Almeida e Silveira \& Eto.

Esperamos que os trabalhos cuidadosamente publicados na $45^{\mathrm{a}}$ edição da Revista, venham contribuir para iluminar o conhecimento ortodôntico e a prática clínica de nossos leitores. Reconhecemos que a variabilidade dos fatores envolvidos na reabsorção radicular, assim como as possibilidades de erro e acerto advindas do tratamento ortodôntico em si, continuam a ser um desafio técnico ao seu controle na clínica. Entretanto, com as evidências reunidas até o presente momento, o "fantasma" da reabsorção dentária começa a ser "exorcizado". Portanto, prezados leitores esperamos que desfrutem desta riquíssima e histórica edição especial!

Adilson Luiz Ramos Editor 